of the suppurating centre has been constant. The author would group these together as retro-antral or mastoido-occipital cases. Examining 100 skulls, Stanculéanu and Depoutre found retro-antral cells in 40 , all connected with the lateral sinus, and most, but not all, communicating with the antrum. Infection travels from the antrum to the retro-antral cells in most cases, probably viâ the blood or lymph stream, and not by a direct route. The pus may escape by three routes, viz: (1) Outwards, (2) into the antrum, or (3) inwards into the cranial cavity (Moure's fatal case), or by two of these routes at one time (case of Taptas). Arthur $J$. Hutchison.

Wilson, T. Stacey.-Otitis Media and Pneumonia. "The Birmingham Medical Review," July, 1901.

The author believes that otitis media is present in most fatal cases of pneumonia. He lays stress on the fact that, although this complication is a frequent occurrence, the classic symptoms usually associated with the disease may be absent. He recommends the "desirability of examining the ears in every case of severe acute pneumonia in children and young people."

Pain may be absent; the hearing in the healthy ear may be so good that the deafness in the affected one is either overlooked or attributed to the dulness which might be the natural result of the fever. Discharge is of little value as a symptom, as when this takes place the danger of pyæmia is usually over.

Some of the symptoms which should cause the observer to examine the ear for the source of pyæmic infection are the following: Slight pain, with or without tenderness in the limbs; abdominal pain or tenderness, often accompanied by distension; diarrhœa about the fifth or sixth day; skin eruptions; small boils, singly or in groups; meningitis, or signs of meningeal irritation.

An incision of the membrana tympani is usually followed by a subsidence of the symptoms. Anthony McCall.

\title{
THYROID, Etc.
}

Charlton, George A. (Montreal).-Frequency and Distribution of Goitre in the Island of Montreal. "Montreal Medical Journal," August, 1901.

In an exhaustive article the writer gives the methods and results of his investigation. The Island of Montreal covers an area of thirty miles by ten. It is situated in the mouth of the Ottawa River, at its juncture with the St. Lawrence. In general configuration the island is a plain, gently sloping from Mount Royal, a rocky elevation of 800 feet, down to the water's edge. The main body of the island is about 60 feet above sea-level.

The soil varies from a few inches to several feet in depth, lying mainly upon Silurian limestone, with here and there an outcrop of Lower Laurentian. Natural springs are few and marshes scarce, although the surface-water remains a long time in early spring, as well as after heavy rain.

Regarding water-supply, the citizens of Montreal and the villagers living near the shore use river-water, derived chiefly from the Ottawa, which is soft, and contains a low percentage of salts of lime. Those 
living inland depend on wells for water-supply. These are shallow, many of them sandy, and invariably contain more or less of surfacewater.

Natives of the city are rarely affected with goitre, but in the surrounding parishes the disease is common. It is found most frequently in girls about the age of puberty, and somewhat rarely among males. The condition occurs in all degrees of severity, but the milder forms are commonest. One remarkable feature is that, exclusive of the city of Montreal, a gradual increase of ratio exists from east to west.

Notwithstanding these differences, varying between almost 0 per cent. in the city, 1.5 per cent. in the east, and 7 per cent. in the west, there are no climatic differences. The inhabitants of the various parishes are engaged in similar pursuits, and the mode of life is the same throughout, all being well fed and comfortably housed. Neither is nationality a factor in the production of the disease; for although the bulk of the people are French, the condition proportionately is as common among English, Irish, and Scotch.

The water-supply appears to be the only point upon which there is material difference. Where the wells are shallowest and most sandy the percentage of cases of goitre is largest. Where they are deep, or even shallow with a clay bottom, the percentage is smaller. Where the river-water is used they are smallest of all.

From a long series of tables given the following may be quoted :

Parishes outside the City, but cpon the Island of Montreal.

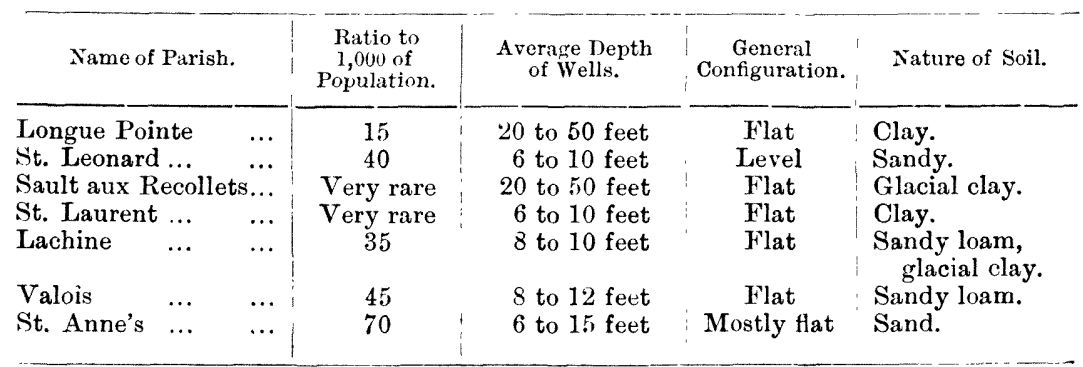

From these facts it would appear that sandy soil, together with the lime-water from shallow wells, were the chief factors favouring the development of the disease.

Price-Brown.

\section{THERAPEUTICS.}

Dubreuilh, W.-Eruptions due to Orthoform. "La Presse Méd.," May 18, 1901.

In the discussion during the recent meeting of the British Medical Association on the local treatment of laryngeal tuberculosis, it was generally agreed that orthoform was the best analgesic in cases of dysphagia, etc., due to tuberculous ulceration of the larynx. No mention was made of any bad effects produced by the drug. The authors who first wrote on orthoform considered it quite innocuous. Experiments on animals showed that immense doses were tolerated without any poisonous effects being produced, but clinical experience proves that in a certain number of cases serious affections, both general 